\title{
Ultra Deep Water Drilling Riser Design and Relative Technology
}

\author{
J. Guesnon ${ }^{1}$, Ch. Gaillard' and F. Richard ${ }^{1}$ \\ 1 Institut français du pétrole, 1 et 4, avenue de Bois-Préau, 92852 Rueil-Malmaison Cedex - France \\ e-mail: jean.guesnon@ifp.fr - christian.gaillard@ifp.fr - florence.richard@ifp.fr
}

\begin{abstract}
Résumé - Risers de forage en offshore profond et technologies associées — L'IFP a développé des outils et des technologies répondant aux attentes des contracteurs de forage qui veulent forer en offshore profond, dans des conditions d'environnement sévères avec des densités de boue élevées. La méthodologie proposée vise à optimiser le dimensionnement des risers de forage en proposant des règles pratiques de design et un logiciel approprié.

Pour réduire les temps morts en opération, un connecteur de riser de forage, le Clip Riser, a été développé. Il permet la connexion rapide des joints de riser. Cette technologie est unique car elle ne comporte aucun écrou ni filetage et ne requiert pas de précontrainte dans le connecteur lors de l'assemblage.

Pour réduire la masse des équipements sur les bateaux de forage ainsi que la tension en tête du riser, l'IFP a mis au point une technologie appelée «tubes frettés» (tubes acier/composite). Ces tubes frettés pourront être utilisés pour remplacer les lignes de sécurité du riser de grand diamètre (kill and choke lines $\phi 114,3 \mathrm{~mm}$ ) par des lignes deux fois plus légères.

Afin d'améliorer le comportement axial du riser, l'intégration hyperstatique des lignes de sécurité a été envisagée. Cette intégration consiste à solidariser les lignes aux extrémités de chaque connecteur si bien qu'elles participent à la résistance axiale du riser. Les avantages de ce système seront présentés dans cet article.

Finalement, toutes ces technologies et tous ces outils devront répondre aux attentes des contracteurs de forage et permettre ainsi de repousser les limites des risers à des profondeurs plus grandes et des conditions opérationnelles plus sévères.

Mots-clés : riser, forage, offshore profond, dimensionnement.
\end{abstract}

\begin{abstract}
Ultra Deep Water Drilling Riser Design and Relative Technology - IFP has developed tools and technology to answer the waiting of contractors that wish to drill in deeper water depths, in harsher environment with higher mud weight. The methodology aims to optimise the riser design by proposing practical guidelines implemented by a software.

To reduce unproductive time on the rig during the drilling, the Clip Riser has been developed. The main feature of the Clip Riser is the coupling which allows quick make-up of the riser. The clip technology is a unique design which does not require bolts, threads or any preloading in operation.

To reduce drillship deckload and required tensioning capacity, the hybrid tubes have been developed to replace the existing 4"1/2 ID (114.3 mm) steel kill and choke lines by lighter tubes. The hybrid tubes are $50 \%$ lighter than equivalent all steel lines. Advantages of this technology will be presented in this paper. To improve axial behavior of the riser and riser architecture, hyperstatic integration of choke and kill lines have been studied. This consists in fixing the auxiliary lines at each riser joint so that they can participate to the axial resistance of the riser. Advantages of this system will be presented in this paper.
\end{abstract}


Finally, the technological developments should answer the waiting of contractors and will further expand the range of application of standard riser systems and make them well suited for ultra deep drilling in very harsh operational and oceanographic environments.

Keywords: drilling riser, ultra deep water, design.

\section{NOTATIONS}

$\alpha_{\delta} \quad$ Riser foot angle for unit rig offset (zero current)

$\beta_{c} \quad$ Riser foot angle due to current (with zero rig offset)

$\delta \quad$ Rig offset

$\Delta^{B M} \quad$ Apparent weight of the buoyancy modules (negative sign)

$\Theta \quad$ Riser foot angle

$\rho_{\text {water }} \quad$ Density of the sea water

$\vec{a}_{n} \quad$ Normal wave acceleration

$\vec{a}_{t} \quad$ Tangential wave acceleration

$\ddot{\vec{x}}_{n o} \quad$ Normal structure acceleration

$\ddot{\vec{x}}_{t o} \quad$ Tangential structure acceleration

$\Delta \vec{v}_{n} \quad$ Normal fluid velocity

$\Delta \vec{v}_{t} \quad$ Tangential fluid velocity

$C_{d n} \quad$ Normal drag coefficient

$C_{d t} \quad$ Tangential drag coefficient

$C_{m n} \quad$ Normal added mass coefficient

$C_{m t} \quad$ Tangential added mass coefficient

$d_{\xi} \quad$ Diameter of the structure

E Young's modulus of the material

$F_{\text {(wave) }}$ Normal inertia force due to wave

$F_{\text {(wave) } t}$ Tangential inertia force due to wave

$F_{d n} \quad$ Normal drag force

$F_{d t} \quad$ Tangential drag force

$F_{i n} \quad$ Normal inertia force

$F_{i t} \quad$ Tangential inertia force

$I \quad$ Inertia of the riser

$P_{e} \quad$ External pressure

$P_{i} \quad$ Internal pressure

$q(z) \quad$ Lateral loads induced by the current

$S_{e} \quad$ External or displaced aera

$S_{i} \quad$ Internal sectional area

$S_{\text {seal }} \quad$ Seal sectional area

$T^{A L} \quad$ Tension in the auxiliary lines

$T_{\text {bottom }}$ Residual effective tension at the riser lower end

$T^{\text {connector }}$ Tension in the connector

$T_{\text {effective }}$ Effective tension

$T^{M P} \quad$ Tension in the main pipe
$T_{\text {Top }} \quad$ Top tension of the riser

$T_{t w} \quad$ True wall tension - axial tension in the pipe

$W^{A L} \quad$ Apparent weight of the auxiliary lines

$W^{\text {misc }} \quad$ Apparent weight of the other miscellaneous components

$W^{M P} \quad$ Apparent weight of the main pipe

$W^{\text {mud }} \quad$ Apparent weight of the riser internal fluid

$W^{\text {riser }} \quad$ Apparent weight of the riser

y Lateral static displacement

$z \quad$ Height above the riser foot.

\section{Superscripts}

$\begin{array}{ll}A L & \text { Auxiliary lines } \\ M P & \text { Main pipe. }\end{array}$

\section{INTRODUCTION}

The riser is the key element for drilling in ultra-deep water. Its architecture for deepwater drilling depends on numerous different factors related to operational and environmental conditions. These include water depth, mud weight, auxiliary line diameters and working pressures, sea states and current profiles, and maximum rig offset. All of the above parameters have to be taken into account in the design of the various riser system components including the main tube, the auxiliary lines, the connectors, the distribution of buoyancy modules, and the tensioning system.

Major concerns of drilling contractors are to run and retrieve the riser fast and to operate it safely in ultra-deep water.

Thus, to answer these queries, the Institut français $d u$ pétrole (IFP) has developed methodology and new technology for expanding the range of application of risers systems and make them well suited for ultra-deep drilling in very harsh operational and oceanographic environments.

The main purpose of the methodology is to optimise the riser design to determine the working envelopes.

The Clip Riser has been developed to allow very fast and safe make up and break out of the riser joints during running and retrieving. Two systems have been already built for Pride International. They are at present being operated for Pride International on the drillships Pride Africa and Pride Angola.

The use of light weight hybrid steel/composite kill and choke lines in order to reduce riser mass and weight on deck 
and to improve axial dynamic behavior in the hung-off mode is being presently undertaken at IFP.

The hyperstatic auxiliary lines designed to participate in the axial strength of the riser allowing reduction in the riser section, reduced fatigue stresses and decreased resonant periods in deep water are also studied.

All these improvements will contribute to better understand the behavior of riser and to upgrade standard-riser applications and enable them to drill in deeper water depths, in harsh environments with higher mud weight.

This paper will present successively:

- basic mechanics of drilling riser and a practical methodology to optimise the riser design according to API $16 Q$ [1] recommendations;

- details of Clip Riser technology;

- development of lightweight hybrid steel/composite choke and kill lines;

- hyperstatic integration system for auxiliary lines.

\section{BASIC MECHANICS}

\section{OF DRILLING RISERS/METHODOLOGY TO OPTIMISE THE RISER DESIGN}

\subsection{Basic Mechanics of Drilling Risers}

\subsubsection{Effective Tension and True Wall Tension}

Effective tension ( $T_{\text {effective }}$ ) is fundamental to the calculation of riser behavior, since it is the tension that governs the curvature and stability of individual riser elements as well as global riser [2]. The difference between effective tension and the true wall tension must first be recalled.

For a single pipe the relation between these two tensions can be expressed most clearly as follows:

$$
T_{\text {effective }}=T_{t w}+\left(-P_{i} S_{i}\right)-\left(-P_{e} S_{e}\right)
$$

where:

$\left(-P_{i} S_{i}\right)$ is the "axial tension" in the internal fluid column;

$\left(-P_{e} S_{e}\right)$ is the "axial tension" in the displaced fluid column.

Hence effective tension is the sum of the "tensions" in the pipe wall and the internal fluid column less the "tension" in the displaced fluid column. For a riser composed of several tubes, such as a drilling riser, Equation (1) can be used to analyse the stability of individual tubes that make up the riser, such as the auxiliary lines.

When analysing the global behavior of the complete riser Equation (1) must be replaced by the following:

$$
T_{\text {effective }}^{\text {riser }}=\sum T_{t w}+\sum\left(-P_{i} S_{i}\right)-\sum\left(-P_{e} S_{e}\right)
$$

The effective tension at any point $(z)$ of the riser can be most easily obtained by considering the top tension $\left(T_{\text {top }}\right)$ and the apparent weight $(W)$ of the intervening section of riser with its contents according to the following equation:

$$
T_{\text {effective }}^{\text {riser }}(z)=T_{\text {Top }}-\sum_{z}^{\text {top }}\left(W^{\text {riser }}+W^{\text {mud }}\right)
$$

The justification of Equations (1), (2) and (3) is presented in many publications [2].

From Equations (1) and (2) it follows that the effective tension ( $T_{\text {effective }}^{\text {riser }}$ ) in the complete riser is the sum of the effective tensions in all the individual tubes from which the riser is made up:

$$
T_{\text {effective }}^{\text {riser }}=T_{\text {effective }}^{M P}+\sum T_{\text {effective }}^{A L}
$$

This equation is the key to deriving the tensions in the different tubes (main pipe and auxiliary lines) that make up the riser. Once the effective tension has been found in each tube comprising the riser, then Equation (1) allows the corresponding true wall tension and axial stresses to be calculated in each tube.

The lateral static displacementof $(y)$ the riser at height $(z)$ can be derived from the following equation, where $E$ is Young's modulus of the material, $I$ the moment of inertia of the riser and $q(z)$ the lateral loads induced by the current.

$$
\frac{\partial^{2}}{\partial z^{2}}\left(E I \frac{\partial^{2} y}{\partial z^{2}}\right)-\frac{\partial}{\partial z}\left(T_{\text {effective }} \frac{\partial y}{\partial z}\right)=q(z)
$$

For practical riser cases the effective tension must be positive at all points in order to avoid buckling instability.

\subsubsection{Top Tension}

It is important to have an accurate evaluation of riser top tension since it influences the definition of the tensioner system. Top tension ( $\left.T_{\text {top }}\right)$ is the sum of three distinct components as given by the following equation:

$$
T_{\text {Top }}=W^{\text {riser }}+W^{\text {mud }}+T_{\text {bottom }}
$$

The three terms of Equation (1) can be calculated separately according to the specifications of the riser components. For example:

$$
W^{\text {riser }}=W^{M P}+W^{A L}+W^{\text {mud }}+\Delta^{B M}
$$

The required minimum value of the bottom end effective tension $T_{\text {bottom }}$ at the lower flex-joint is determined by consideration of the mean angle at the flexjoint which has to be maintained within the limit of $2^{\circ}$ specified by API $16 Q$ [1]. The minimum tension must also exceed the apparent weight of the LMRP (low marine riser package) in order to assure lift-off in case of an emergency disconnect. In most of the cases, this tension is of the order of 200 kips. 


\subsubsection{Tension in Auxiliary Lines under Pressure}

The auxiliary lines are relatively small-diameter tubes which are fixed to the connector at one extremity of each riser joint and are free to slide at the other end (stab-in connections). Therefore assuming the sealing diameter is equal to the external diameter of the tube, the true wall "tension" in the line is:

$$
T_{t w}^{A L} \approx-P_{i}\left(S_{e}-S_{i}\right)
$$

Hence from Equation (1):

$$
T_{\text {effective }}^{A L}=-\left(P_{i}-P_{e}\right) S_{\text {seal }}^{A L}
$$

When under pressure, the tubes are in effective compression. Intermediate collars are therefore needed to prevent buckling.

\subsubsection{Influence of Auxiliary Line Pressures on the Main Tube Tension}

From Equation (3) it can be seen that internal pressure in one or more of the tubes that make up the riser has no influence on the global riser effective tension. However it does influence the distribution of tension (effective and true wall) between the different tubes that make up the riser.

As has been seen above, an increase in the internal pressure in an auxiliary line causes the effective tension $\left(T_{\text {effective }}^{A L}\right)$ in that line to decrease (to a negative value). But as the global effective tension in the riser remains unchanged (Eq. (3)) it follows from Equation (4) that the effective tension in the main pipe must increase. Hence from Equation (1) the true wall tension of the main pipe also increases. If the pressure in the main tube is unchanged, then:

$$
\delta\left(T_{t w}^{M P}\right)+\sum \delta\left(T_{\text {effective }}^{A L}\right)=0
$$

For real risers, pressure in the auxiliary lines can cause significant additional axial loads in the main pipe of the order of 500 kips $(225 \mathrm{t})$, per line for 15000 psi (103.4 MPa) working pressure and 4 1/2" (114.3 $\mathrm{mm}$ ) diameter sealing. These additional loads must be taken into account when designing the riser.

\subsubsection{Tensile Loads in the Connectors}

The effective tension in the riser connectors is given as before by Equation (3). When deducing the true axial force in the connector lugs, dogs, flange bolts or other connecting elements, it is the "seal" sectional area $\left(S_{\text {seal }}\right)$ within the connector that must be used in the effective tension equation. Hence that equation becomes:

$$
T_{\text {true }}^{\text {connector }}=T_{\text {effective }}^{M P}+\left(P_{i}-P_{e}\right) * S_{\text {seal }}
$$

$T_{\text {effective }}^{M P}$ is normally a maximum at the riser top end. However the effective tension does not generally vary linearly with depth because of two factors. Firstly the main tube wall section is not of constant thickness. It tends to be thinner in the mid-height region than at the upper end, where tension is greatest, and the lower end where bursting stresses are greatest. Secondly buoyancy units tend to be concentrated in the upper section of a riser. Thus $T_{\text {true }}^{\text {connector }}$ tends to have its greatest value at an intermediate point along the riser.

\subsection{Drilling-Riser Design Procedure}

\section{Design Criteria}

The riser has to be designed according to API RP $16 Q$, Table 3.1 [1] requirements and in particular:

- maximum von Mises stresses must be limited to less than 2/3 of yield;

- mean angle at the riser foot has to be less than $2^{\circ}$.

No other quantified specification is listed in this recommendation concerning the riser design. In particular, no recommendations are given concerning corrosion, fatigue, and pressure in the auxiliary lines. IFP has proposed a practical methodology for designing drilling risers to meet particular specifications considering riser behaviour in the connected (drilling mode) and disconnected (hung off mode).

\subsubsection{Connected Drilling Mode}

This is the operating mode for which von Mises stresses must be kept below $2 / 3$ of yield. The following situation should be considered:

- riser connected to the floating vessel through the slip joint and the tensioner system;

- riser full of mud with the maximum density;

- all the auxiliary lines under maximum pressure simultaneously;

- the wall thickness of the main pipe 5\% less than nominal (due to tolerances);

- 1/16" (1.588 mm) decrease of the wall thickness due to corrosion;

- $3 \%$ buoyancy loss of the flotation modules due to water absorption.

\subsubsection{Disconnected Hung off Mode}

In this situation the fluctuating axial tension should remain positive when the vessel heaves in order to avoid any slackening or dynamic buckling of the riser. To meet these criteria, the apparent weight of the hanging riser must be greater than the maximum amplitude of variation of the tension in any point. In this mode, the calculation should take into account the following:

- riser disconnected from the wellhead with the LMRP suspended at the riser lower end; 
- the riser and the auxiliary lines full of sea water;

- the auxiliary lines non-pressurised (hydrostatic pressure);

- the wall thickness of the main pipe 5\% less than nominal;

- loss of 1/16" (1.588 mm) of the wall thickness due to corrosion;

- $3 \%$ buoyancy loss of the flotation modules due to water absorption.

During the design phase, iterative calculations are made between the two modes to optimise the architecture. The wall thickness of each riser section is modified to meet the criteria in the connected mode while the buoyancy ratio of the riser (see explanation below) is adjusted to ensure that no dynamic compression occurs in the disconnected mode.

\subsubsection{Buoyancy Ratio}

The buoyancy ratio is defined as follows:

$$
\text { Buoyancy ratio }=\frac{\Delta^{B M}}{\sum\left(W^{M P}+W^{A L}+W^{\text {misc }}\right)}
$$

The buoyancy ratio is important since it allows the buoyancy module diameter to be fixed. It must be as high as possible so that the top tension can be reduced. However, since the riser must have positive apparent weight in the disconnected hang off mode (to avoid dynamic compression), it is always less than $100 \%$.

\subsection{A practical Methodology to Optimise the Riser Design (Fig. 1)}

Finally, as has been seen above, the architecture of a riser depends on many parameters including operational and environmental conditions. Hence its architecture is specific for particular conditions. Studies must be performed to determine whether a riser can be used in other conditions. For example an increase in water depth may be possible with a reduction of mud density. All parameters must be taken into account before designing a riser. A practical methodology is presented in this part to explain architectures.

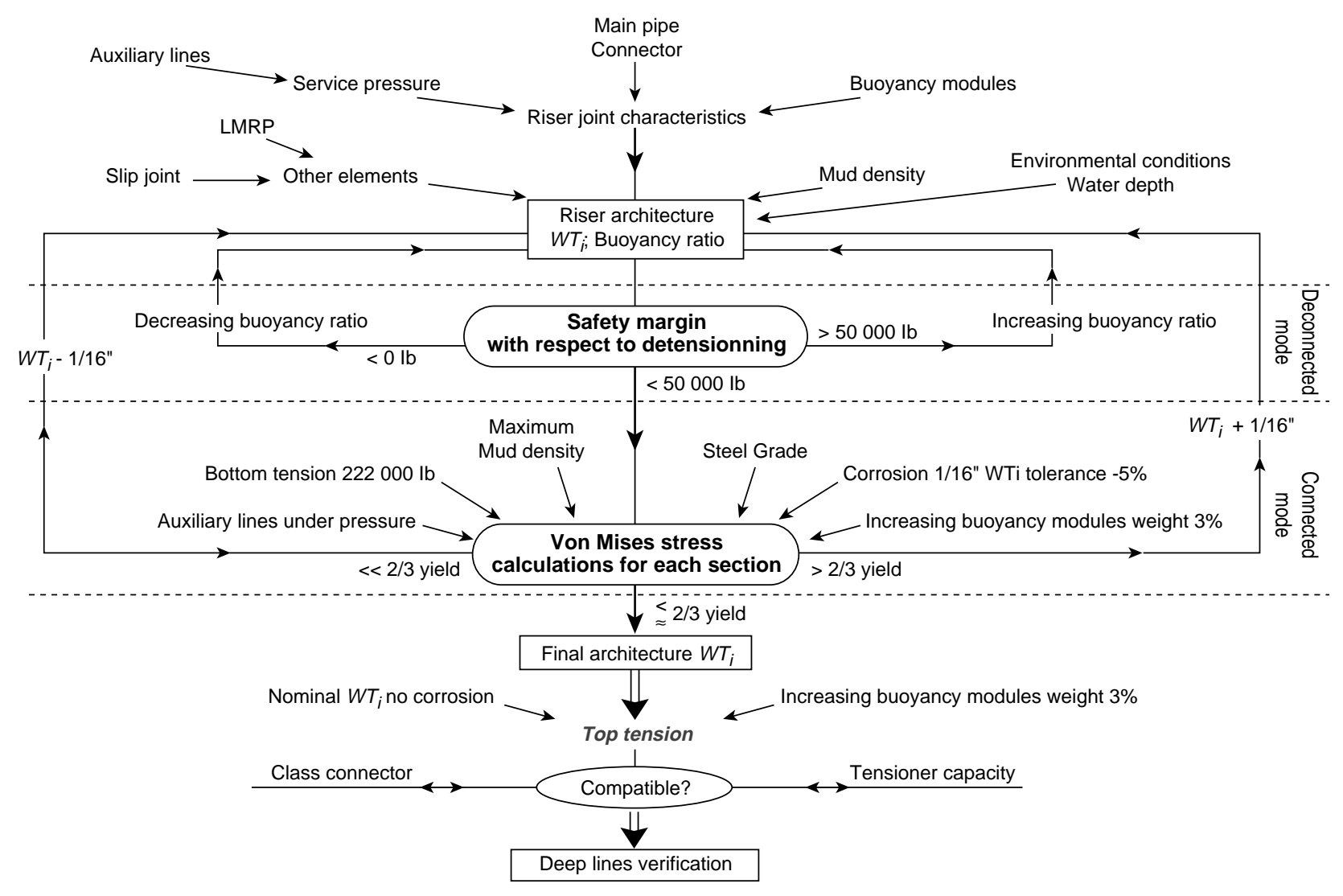

Figure 1

Methodology to optimise the riser design. 
Main factors:

- the environmental conditions and the water depth are fixed by the drill site;

- the maximum density is imposed by the reservoir engineering studies;

- the auxiliary lines are set by the BOP class 10000 psi (69 $\mathrm{MPa})$ or $15000 \mathrm{psi}(103.4 \mathrm{MPa})$;

- the diameter of the riser 21" (533.4 mm) or less is dictated by the drilling program;

- the buoyancy modules, with their maximum depth characteristics, determine the different sections of the riser architecture. These sections are often about $2000 \mathrm{ft}$ long (610 m).

With these elements a preliminary design (i.e. wall thickness for each section) of the riser can be easily made. To optimise this architecture, iterations on the wall thickness of each section have to be performed.

First of all, the criterion in disconnected mode (hard hang off) has to be checked (see design procedure in 1.2.2). The safety with respect to the dynamic tension has to be determined considering 10-year or 100-year wave return periods. If the safety margin is negative, that means the riser may be subjected to dangerous dynamic buckling, so the buoyancy ratio may have to be decreased. If the safety margin is too high, the buoyancy ratio may be increased.

Once the buoyancy ratio has been adjusted for the disconnected mode, calculations have to be performed to check the operating mode (see design procedure in 1.2.1). The von Mises stress criteria have to be checked for each riser section. If the von Mises stresses exceed $2 / 3$ of the yield strength, the wall thickness of this section should be increased by $1 / 16 "(1.588 \mathrm{~mm})$. Conversely, if the stresses are less than $2 / 3$ of yield strength, the wall thickness can be decreased by $1 / 16 "$ " $1.588 \mathrm{~mm})$. After modification of the wall thickness, the safety margin in disconnected mode should be checked again in order to adjust the buoyancy ratio.

This iterative procedure leads to the final design of the complete riser. The maximum top tension can then be deduced in operating mode considering nominal wall thickness of each section, no corrosion and an increasing buoyancy module weight of $3 \%$. This top tension has to be compatible with the tensioner capacity according to the API $16 Q$ recommendation (Section 3.3.2) [1]. Moreover, the class of the connector has to be compatible with the maximum tension calculated according to Equation (9) (including the effect of pressure in the auxiliary lines).

Moreover, each riser joint has to be check with respect to the collapse. In this methodology, it is assumed that a fill up valve is efficient.

Finally, the last stage of the design is the dynamic calculation. The influence of dynamic motions, current profiles, wave conditions on the riser bending, on the bottom angle have to be checked. IFP has developed a finite element software called "Deeplines" [3] to calculate all the parameters in the dynamic mode.

\subsection{Influence of Main Operational and Environmental Parameters}

In the final stages of the design, sensitivity to operational or environmental parameters has to be examined. Their influence on the riser behavior and on the top tension, which is the most important factor with respect to the tensioner capacity, has to be checked. The main parameters, which act directly on the riser, are dealt with below.

\subsubsection{Operational Parameters}

\section{Mud Density}

According to Equation (1), the top tension depends directly on the apparent weight of the mud (as the bottom tension is generally about 200 kips $(\sim 100 \mathrm{t})$, and the apparent weight of the riser may exceed 600 kips $(275 \mathrm{t})$ in very severe conditions to meet the disconnected mode specifications). Risers must be designed with the maximum mud density that may be encountered. The range is from $14 \mathrm{ppg}$ (1.6) to $17 \mathrm{ppg}$ (2.04) in the GOM (Gulf of Mexico) conditions.

For a typical riser in $10000 \mathrm{ft}(3048 \mathrm{~m})$ water depth, an increase of $1 \mathrm{ppg}(0.12)$ of the mud density induces the following:

- an increase in wall thickness of the main pipe of 1/16" $(1.588 \mathrm{~mm})$;

- an increase in buoyancy module diameter of $1 / 2$ " $(12.7 \mathrm{~mm})$;

- an increase in top tension of $175000 \mathrm{lbs}(80 \mathrm{t})$.

Similarly a water depth increase of $1000 \mathrm{ft}$ (305 m) requires $150000 \mathrm{lbs}(70 \mathrm{t})$ of additional top tension because of the increase in mud volume considering 17 ppg (2.04) mud density.

Hence it may be possible to upgrade the water depth of the riser by reducing the mud density range. For example, the water depth of a riser may be increased by $1000 \mathrm{ft}(305 \mathrm{~m})$ just by reducing the maximum mud density by $1 \mathrm{ppg}(0.12)$. It should be noted that the maximum von Mises stresses must also be checked, as well as the no dynamic compression criterion, in the disconnected mode.

\section{Pressure in the Choke and Kill Lines}

The service pressure of choke and kill lines influences riser architecture. The difference between 4"ID $(101.6 \mathrm{~mm}) \times$ $10000 \mathrm{psi}(69 \mathrm{MPa})$ and 4 1/2"ID $(114.3 \mathrm{~mm}) \times 15000 \mathrm{psi}$ (103.4 MPa) working pressure is significant. For example, in GOM configuration, $10000 \mathrm{ft}(3050 \mathrm{~m})$ water depth and 15 ppg (1.8) mud density:

- the wall thickness of the main pipe has to be increased by 2/16" (3.175 mm); 
- the riser mass is increased by $1800000 \mathrm{lbs}(800 \mathrm{t})$;

- the buoyancy module diameter is increased by 6" (152 mm);

- the top tension is increased by $200000 \mathrm{lbs}(90 \mathrm{t})$.

Clearly it is not possible to upgrade choke and kill lines from 3" (76.2 mm to $41 / 2 "(114.3 \mathrm{~mm})$ ID without making considerable changes to the riser architecture.

\section{Disconnected Mode}

The required buoyancy ratio of the riser, to avoid inducing dynamic compression at the riser top end, depends on which hang off mode is chosen (hard or soft hang off).

With the "hard hang off", the riser is supported directly on the dogs of the spider (with the telescopic joint removed). The heave motion of the vessel is transmitted directly to the riser and may induce dynamic tensions at the riser top end sufficient to put the riser into effective compression. This situation is unacceptable. This leads to a required buoyancy ratio of about $80-85 \%$ for $10000 \mathrm{ft}(3048 \mathrm{~m})$ water depth. Its precise value depends on the response amplitude operator (RAO) of the vessel which varies with the vessel type (dynamically positioned drillship, semi-sub).

In the "soft hang off", the riser is suspended from the tensioners and the heave motion transmitted to the riser is greatly reduced [4]. Thus the buoyancy ratio can be increased significantly (up to 95\%) allowing a corresponding reduction in top tension, but leading to an increase in buoyancy module diameter.

Hence the architecture of a riser may be significantly different in terms of top tension and buoyancy module diameter, depending on which hang off mode is adopted. However, the "soft hang off" is not studied in this paper since its reliability in extreme conditions has yet to be proved.

\section{Buoyancy Module Distribution}

Different configurations of buoyancy module distribution can be considered:

- all riser joints equipped with buoyancy modules;

- some joints in the lower part of the riser without buoyancy modules.

The second configuration has many advantages and a few disadvantages:

- less buoyancy modules required (but larger diameter);

- more regular stress distribution along the riser;

- better behavior in disconnected mode (natural period shorter by about $10 \%$ and dynamic tension reduced by about $10 \%$ ).

The main disadvantage of this architecture is the increased tensile load in the connector $220000 \mathrm{lbs}(100 \mathrm{t})$. Thus, if the class of the connector is the limiting factor, the riser should preferably to be designed with all joints equipped with buoyancy modules. This is particularly the case when a riser is designed for harsh environments such as the GOM in very deep water (10 $000 \mathrm{ft}(3000 \mathrm{~m})$, with heavy mud density)
17 ppg (2.04). In this particular case, the static maximum tension in the connectors may theoretically exceed $3000000 \mathrm{lbs}$ (1350 t) when $15000 \mathrm{psi}(103.4 \mathrm{MPa})$ working pressure is applied in choke and kill lines. The class of the connector has to be chosen in consequence.

\section{Influence of the LMRP Apparent Weight}

Increasing the apparent weight of the LMRP allows the buoyancy ratio of the riser to be slightly increased and thus the top tension to be slightly decreased. The LMRP apparent weight plays a significant role in the disconnected mode since it reduces the risk of dynamic compression in the hung off riser. See the example (Table 1) for $10,000 \mathrm{ft}(3050 \mathrm{~m})$ water depth, $15000 \mathrm{psi}$ (103.4 MPa) working pressure and GOM conditions.

TABLE 1

Influence of LMRP weight

\begin{tabular}{lr|c|c}
\hline Apparent weight of LMRP & $\begin{array}{r}(\mathrm{lbs}) \\
(\mathrm{t})\end{array}$ & $\begin{array}{c}140000 \\
65\end{array}$ & $\begin{array}{c}280000 \\
130\end{array}$ \\
\hline Buoyancy ratio & & $80 \%$ & $83 \%$ \\
\hline Top tension & $(\mathrm{lbs})$ & 2600000 & 2500000 \\
& $(\mathrm{t})$ & 1170 & 1130 \\
\hline
\end{tabular}

\subsubsection{Environmental Parameters}

Water Depth

The design water depth is plainly one of the major starting points for the riser design and will not be discussed here further. It should be noted however that the number of bare joints as well as the BOP (blow out preventer) and LMRP weights have to be checked versus the hook load capacity during the deployment phases.

\section{Current}

The current profiles and intensity (associated with the rig offset) determine the riser top and bottom end angles. According to API RP 16Q [1], in the drilling connected mode these angles have to be less of $2^{\circ}$ in static conditions (no waves) and $4^{\circ}$ in dynamic. However for deepwater risers with high top tensions, the dynamic riser foot angle variation is extremely small (typically less than $0.2^{\circ}$ ). Hence a static analysis is generally sufficient to assess the riser top and bottom end angles.

The current load on the riser is calculated using Morison's Equation based on relative fluid flow assumptions. The body is considered to be sufficiently slender not to disturb the incoming flow. The table 2 summarises various expressions used for normal, and tangential hydrodynamic loads on the riser string for static and dynamic analysis (drag + inertia).

Since the drag force is proportional to the square of the current velocity, doubling that velocity increases the drag load by a factor of 4 . 
Furthermore the hydrodynamic load is directly proportional to the drag coefficient $(C d)$ used in the numerical model. The choice of the drag coefficient to consider depends on the flow regime (Reynolds number and Keulegan and Carpenter number).

\section{TABLE 2}

Hydrodynamic loads on the riser

\begin{tabular}{c|c}
\hline $\begin{array}{c}\text { Drag force due } \\
\text { the relative fluid velocity }\end{array}$ & Morison's Equation terms \\
\hline normal & $\vec{F}_{d}=\frac{1}{2} d_{\xi} \rho_{\text {water }} C_{d_{n}}\left\|\Delta \vec{v}_{n}\right\| \Delta \vec{v}_{n}$ \\
\hline tangent & $\vec{F}_{t}=\frac{1}{2} d_{\xi} \rho_{\text {water }} C_{d_{t}}\left\|\Delta \vec{v}_{t}\right\| \Delta \vec{v}_{t}$ \\
\hline $\begin{array}{c}\text { Inertia force due } \\
\text { to the structure acceleration }\end{array}$ & $\vec{F}_{\text {in }}=-\frac{\pi d_{\xi}^{2}}{4} \rho_{\text {water }}\left(C_{m_{n}}-1\right) \ddot{\vec{x}}_{n_{o}}$ \\
\hline normal & $\vec{F}_{i t}=-\frac{\pi d_{\xi}^{2}}{4} \rho_{\text {water }}\left(C_{m_{t}}-1\right) \ddot{\vec{x}}_{t_{o}}$ \\
\hline $\begin{array}{c}\text { tangent } \\
\text { Inertia force due } \\
\text { to the wave acceleration }\end{array}$ & $\vec{F}_{\text {(wave) } n}=\frac{\pi d_{\xi}^{2}}{4} \rho_{\text {water }} C_{m_{n}} \vec{a}_{n \text { (wave) }}$ \\
\hline normal & $\vec{F}_{\text {(wave) } t}=\frac{\pi d_{\xi}^{2}}{4} \rho_{\text {water }} C_{m_{t}} \vec{a}_{t(\text { wave) }}$ \\
\hline tangent
\end{tabular}

which could be complex. For instance, a bare joint with auxiliary Kill and Choke and booster lines induces a complex flow dependant of the current heading versus the lines arrangement and according to the pipe roughness.

The drag coefficients to be chosen for numerical analysis are generally derived from literature or rules/guidelines. Some specific 2D computational fluid dynamic analysis [5] (with current and current + waves) has confirmed that the maximum values of the drag coefficients that the maximum values of the drag coefficients provided by API RP16Q [1] are realistic for Reynolds numbers ranging between $10^{5}$ and $10^{6}$. So the following values could be taken:

- a value of $C d=2$ for a bare joints (with a reference diameter of the main bare tube e.g. 21" (533.4 mm) OD diameter);

- a value of $C d=1.2$ for buoyant joints with cylindrical foam modules (with reference to diameter of buoyancy modules).

The angles at the riser extremities have components due to the rig offset and the current load. The law of superposition applies to these components [5]. Hence the riser foot angle $(\Theta)$ for a given offset can be calculated as follows:

$$
\Theta(\delta) \cdot \alpha_{\delta}+\beta_{c}
$$

Sometimes in strong currents, a residual bottom end tension greater than standard 200 kips $(90 \mathrm{t})$ may be required to keep the bottom angle within the acceptable range. The operational procedure may be to offset the DP rig upstream to reduce the riser foot angle.

Waves

Wave action influences riser design in two ways:

- it contributes to the hydrodynamic loads acting on the riser; - it affects the riser top end motions through the rig RAO's.

The first point is taken into account using Morison's Equation with relative flow assumptions. For annual wave conditions, the effect of current is generally predominant in the fluid velocity flows compared to the wave particle velocities. Moreover, the wave particle velocities decrease exponentially with water depth. Hence the contribution of wave action to riser hydrodynamic loads remains limited.

Rig motions are more significant for deepwater riser design. They have a major influence on riser behavior particularly in the disconnected mode.

\subsection{Examples of Riser Architectures in $10000^{\prime}(3050 \mathrm{~m})$ Water Depth}

The three examples presented in this part are specific to 10 000' (3050 m) water depth.

- Case 1 considers Gulf of Guinea conditions.

- Case 2 and 3 are specific Gulf of Mexico environment. The differences between the cases are related to the choke and kill line characteristics which are given in Table 3.

Case 3 corresponds to choke and kill lines with a steel core hoop wound with a carbon thermoplastic strip. These hybrid lines (steel/composite) have 1/2" (12.7 mm) wall thickness and 3/16" (5 mm) of composite. The mass of such lines is $50 \%$ less than the equivalent all steel tubes with 1" (25.4 mm) wall thickness.

The different architectures have been designed according to the design procedure presented in the previous section. The criteria in the disconnected mode and in operating conditions respect API 16Q [1].

TABLE 3

Details of the cases studied

\begin{tabular}{c|c|c|c|c}
\hline & Environment & $\begin{array}{c}\text { Internal } \\
\text { diameter }\end{array}$ & $\begin{array}{c}\text { Service } \\
\text { pressure }\end{array}$ & $\begin{array}{c}\text { Max mud } \\
\text { density }\end{array}$ \\
\hline Case 1 & GOG & $\begin{array}{c}4 " \\
101.6 \mathrm{~mm}\end{array}$ & $\begin{array}{c}10000 \mathrm{psi} \\
69 \mathrm{MPa}\end{array}$ & $\begin{array}{c}15 \mathrm{ppg} \\
1.8\end{array}$ \\
\hline Case 2 & GOM & $\begin{array}{c}4 " 1 / 2 \\
114.3 \mathrm{~mm}\end{array}$ & $\begin{array}{c}15000 \mathrm{psi} \\
103.4 \mathrm{MPa}\end{array}$ & $\begin{array}{c}17 \mathrm{ppg} \\
2.04\end{array}$ \\
\hline Case 3 & GOM & $\begin{array}{c}4 " 1 / 2 \text { hybrid } \\
114.3 \mathrm{~mm} \text { hybrid }\end{array}$ & $\begin{array}{c}15000 \mathrm{psi} \\
103.4 \mathrm{MPa}\end{array}$ & $\begin{array}{c}17 \mathrm{ppg} \\
2.04\end{array}$ \\
\hline
\end{tabular}

* GOG: Gulf of Guinea, GOM: Gulf of Mexico. 
TABLE 4

Details of the different architecture

\begin{tabular}{|c|c|c|c|}
\hline $\begin{array}{l}\text { Kill and choke } \\
\text { lines }\end{array}$ & Case 1 & Case 2 & Case 3 \\
\hline \multicolumn{4}{|c|}{ Water depth = 10000} \\
\hline Environment & GOG & GOM & \\
\hline $\begin{array}{c}\text { Top } \\
\text { Architecture }^{(1)} \\
\text { Bottom }\end{array}$ & $\begin{array}{c}26 \times \mathrm{RJ}-12 \mathrm{~B} 2 \\
27 \times \mathrm{RJ}-11 \mathrm{~B} 4 \\
26 \times \mathrm{RJ}-11 \mathrm{~B} 6 \\
27 \times \mathrm{RJ}-11 \mathrm{~B} 8 \\
26 \times \mathrm{RJ}-12 \mathrm{~B} 10\end{array}$ & $\begin{array}{c}26 \times \mathrm{RJ}-16 \mathrm{~B} 2 \\
27 \times \mathrm{RJ}-15 \mathrm{~B} 4 \\
26 \times \mathrm{RJ}-15 \mathrm{~B} 6 \\
27 \times \mathrm{RJ}-15 \mathrm{~B} 8 \\
26 \times \mathrm{RJ}-16 \mathrm{~B} 10 \\
\end{array}$ & $\begin{array}{c}26 \times \mathrm{RJ}-16 \mathrm{~B} 2 \\
27 \times \mathrm{RJ}-15 \mathrm{~B} 4 \\
26 \times \mathrm{RJ}-15 \mathrm{~B} 6 \\
27 \times \mathrm{RJ}-15 \mathrm{~B} 8 \\
26 \times \mathrm{RJ}-16 \mathrm{~B} 10 \\
\end{array}$ \\
\hline $\begin{array}{l}\text { Buoyancy module } \\
\text { diameter (inch) } \\
(\mathrm{mm})\end{array}$ & $\begin{array}{c}45 \\
1140\end{array}$ & $\begin{array}{c}53 \\
1346\end{array}$ & $\begin{array}{c}50 \\
1270\end{array}$ \\
\hline $\begin{array}{l}\text { Axial natural } \\
\text { period }(\mathrm{s})\end{array}$ & 4.6 & 5.0 & 4.7 \\
\hline $\begin{array}{l}\text { Riser mass }(\mathbf{l b})(\mathbf{t}) \\
\text { Main tube }\end{array}$ & $\begin{array}{c}2000000 \\
900\end{array}$ & $\begin{array}{c}2478000 \\
\quad 1115\end{array}$ & $\begin{array}{c}2478000 \\
\quad 1115\end{array}$ \\
\hline Kill and choke lines & $\begin{array}{c}738000 \\
332\end{array}$ & $\begin{array}{c}1351000 \\
609\end{array}$ & $\begin{array}{c}755000 \\
340\end{array}$ \\
\hline Booster/hyd. lines & $\begin{array}{c}487000 \\
219\end{array}$ & $\begin{array}{c}487000 \\
219\end{array}$ & $\begin{array}{c}487000 \\
219\end{array}$ \\
\hline Buoyancy modules & $\begin{array}{c}24000000 \\
1080\end{array}$ & $\begin{array}{c}3184000 \\
1433\end{array}$ & $\begin{array}{c}2771000 \\
1247\end{array}$ \\
\hline Total & $\begin{array}{c}5625000 \\
2531 \\
\end{array}$ & $\begin{array}{c}7500000 \\
3376 \\
\end{array}$ & $\begin{array}{c}6491000 \\
2921 \\
\end{array}$ \\
\hline $\begin{array}{l}\text { Riser app. weight } \\
\text { (lb) (t) }\end{array}$ & & & \\
\hline Main tube & $\begin{array}{c}1740000 \\
783\end{array}$ & $\begin{array}{c}2151000 \\
968\end{array}$ & $\begin{array}{c}2151000 \\
968\end{array}$ \\
\hline Kill and choke lines & $\begin{array}{c}580000 \\
261\end{array}$ & $\begin{array}{c}1112000 \\
268\end{array}$ & $\begin{array}{c}594000 \\
268\end{array}$ \\
\hline Booster/hyd. lines & $\begin{array}{c}422000 \\
190\end{array}$ & $\begin{array}{c}422000 \\
190\end{array}$ & $\begin{array}{c}422000 \\
190\end{array}$ \\
\hline Buoyancy modules & $\begin{array}{c}-2120000 \\
-954 \\
\end{array}$ & $\begin{array}{c}-2862000 \\
-1288 \\
\end{array}$ & $\begin{array}{c}-2473000 \\
-1113 \\
\end{array}$ \\
\hline Total & $\begin{array}{c}622000 \\
280 \\
\end{array}$ & $\begin{array}{c}829000 \\
373 \\
\end{array}$ & $\begin{array}{c}698000 \\
314 \\
\end{array}$ \\
\hline $\begin{array}{l}\text { Riser app. weight } \\
\text { (lb) } \\
\text {-17 ppg (2.04 SI) } \\
\text { (t) }\end{array}$ & $\begin{array}{c}1116000 \\
502 \\
\end{array}$ & $\begin{array}{c}1442000 \\
649 \\
\end{array}$ & $\begin{array}{c}1447000 \\
651 \\
\end{array}$ \\
\hline $\begin{array}{l}\text { Bottom tension }^{(2)} \\
\text { (lb) (t) }\end{array}$ & $\begin{array}{c}222000 \\
100\end{array}$ & $\begin{array}{c}222000 \\
100\end{array}$ & $\begin{array}{c}222000 \\
100\end{array}$ \\
\hline $\begin{array}{l}\text { Top tension }{ }^{(3)} \\
\text { (lb) (t) }\end{array}$ & $\begin{array}{c}2070000 \\
932\end{array}$ & $\begin{array}{c}2600000 \\
1172\end{array}$ & $\begin{array}{c}2478000 \\
1115\end{array}$ \\
\hline
\end{tabular}

(1) Composition of the riser from top to bottom explanation of joint nomenclature: 27 x RJ-15B4

- 27: number of joints in this section

- RJ for riser joint

- 15 is the thickness of the riser section in 16th of inch

- B4 means the joint is fitted with buoyancy modules for $4000 \mathrm{ft}(1220 \mathrm{~m})$ water depth.

(2) Bottom tension = typical tension at the lower flex joint level to keep the mean angle to less than $2^{\circ}$.

(3) Top tension = apparent weight of the riser (including slip joint) plus apparent weight of mud plus bottom tension.

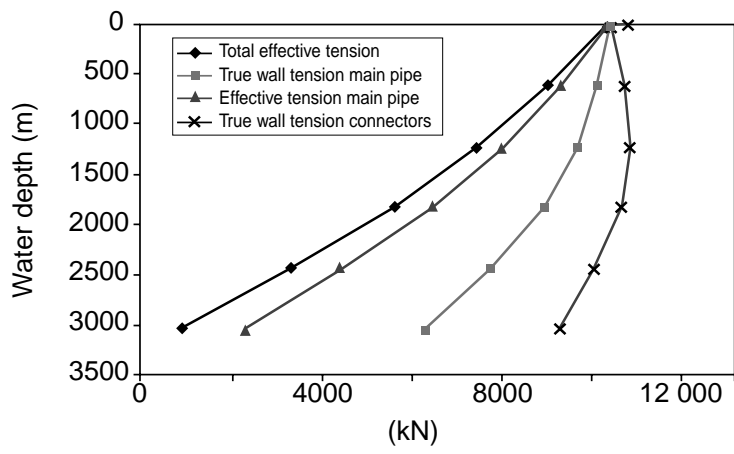

Figure 2

Tensions in the main pipe $(\mathrm{kN})$ versus water depth $(\mathrm{m})$. (Mud density@17,0 ppg | Top tension@1172 t | Pressure: KCl@0ksi-B\&H@0ksi).

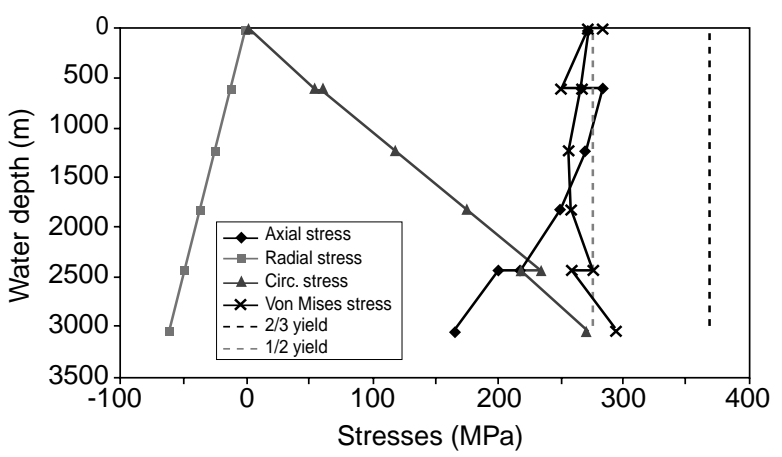

Figure 3

Stresses in the main pipe (MPa) versus water depth (m) (Mud density@17.0ppg | Top tension@1172 t | Pressure: $\mathrm{KCl} @ 0 \mathrm{ksi}-\mathrm{B} \& \mathrm{H} @ 0 \mathrm{ksi})$.

The different architectures have been designed according to the design procedure presented in the previous section. The criteria in the disconnected mode and in operating conditions respect $A P I 16 Q$ [1].

Note that auxiliary lines can slide at one extremity of each riser joint. Other configuration (type: hyperstatic integration [6] can be used but completely change the whole architecture of these risers. The top tension includes the slip joint apparent weight of $110000 \mathrm{lbs}(50 \mathrm{t})$ and the residual bottom tension of $222000 \mathrm{lbs}(100 \mathrm{t})$. In the disconnected mode, the LMRP apparent weight is equal to $145000 \mathrm{lbs}$ (70 t).

Details of these architectures are presented in the Table 4.

Global results are plotted in Figures 2-12 for case 2 . Differences between true wall tension and effective tension in the main pipe, as well as total effective tension and connector tension are presented in Figure 2. The influence of the pressure in the auxiliary lines is clearly shown in the Figures 4, 5, 7 and 9. When 15000 psi (103.4 MPa) is applied in the choke and kill lines, the increase of axial 


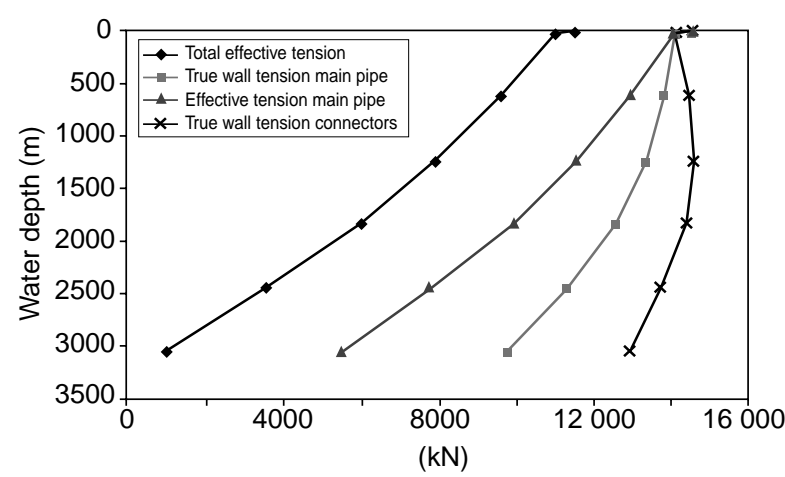

Figure 4

Tensions in the main pipe $(\mathrm{kN})$ versus water depth $(\mathrm{m})$ (Mud density @ 17.0 ppg | Top tension@ 1172 t | Pressure: KCl@10 ksi - B\&H @ 1 ksi).

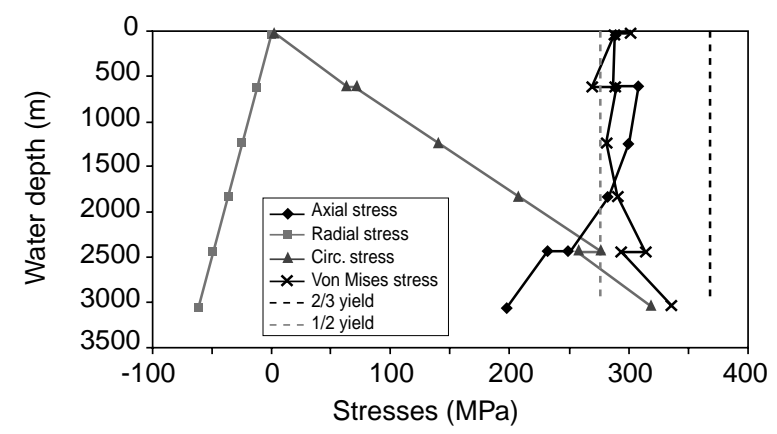

Figure 6

Stresses in the main pipe (MPa) versus water depth (m)

(Mud density@17.0 ppg | Top tension@ 1090 t | Pressure: KCl@0 ksi - B\&H @ 0 ksi).

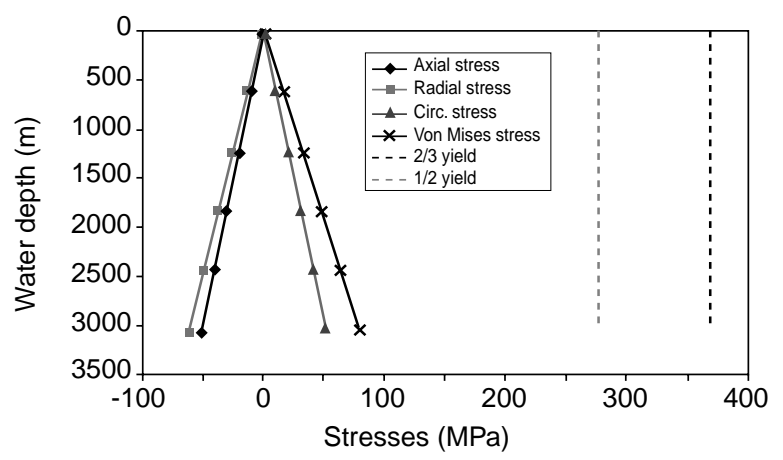

Figure 8

Stresses in the kill and choke lines (MPa) versus water depth (m) (Mud density@17.0 ppg | Top tension@ 1172 t | Pressure: $\mathrm{KCl} @ 0$ ksi - B\&H @ 0 ksi).

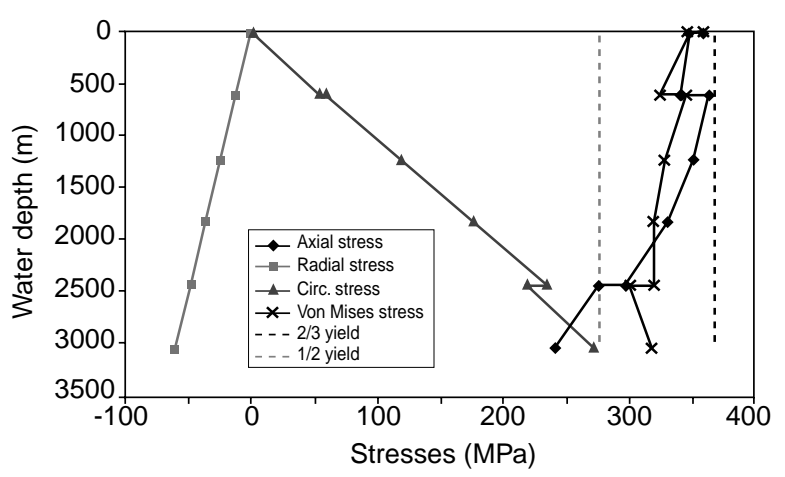

Figure 5

Stresses in the main pipe (MPa) versus water depth (m) (Mud density@17.0ppg|Top tension@1172 t | Pressure: KCl@10 ksi - B\&H @ 1 ksi).

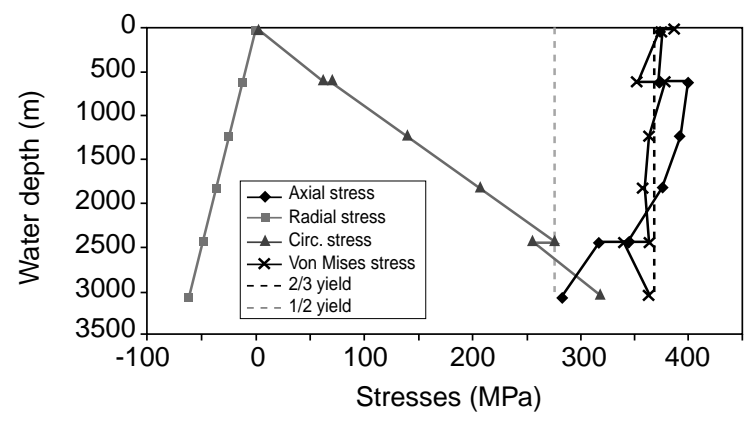

Figure 7

Stresses in the main pipe (MPa) versus water depth (m) (Mud density@17.0 ppg|Top tension@1090 t | Pressure: KCl@10ksi-B\&H @ 1ksi).

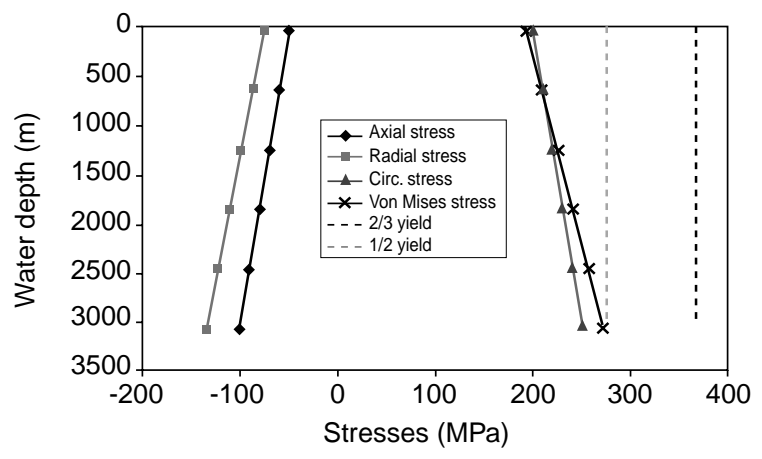

Figure 9

Stresses in the kill and choke lines (MPa) versus water depth (m) (Mud density@17.0 ppg|Top tension@ 1172 t | Pressure: KCl@10 ksi - B\&H @ 1 ksi). 


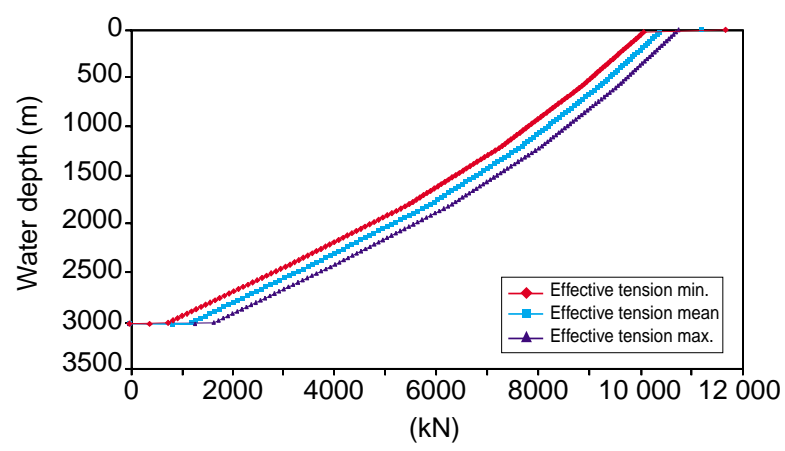

Figure 10

Connected mode - Dynmic analysis - Effective tension. Case 2.

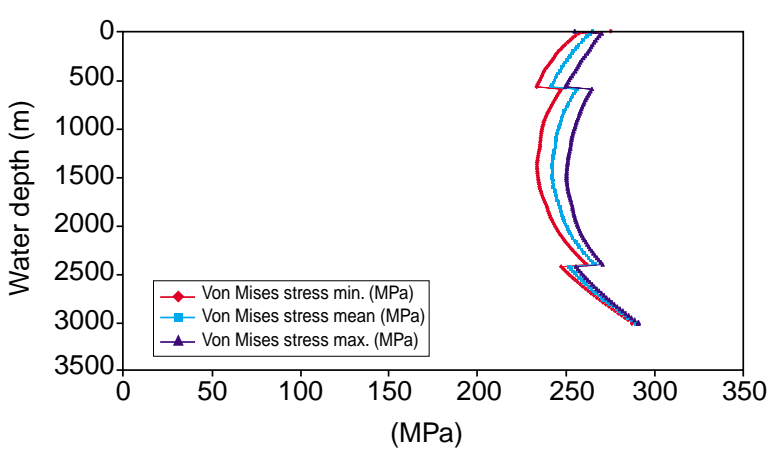

Figure 11

Dynamic stress - Connected mode. Case 2. tension in the connectors is about 750 kips (340 t). The corrosion is also an important factor to be considered (Figs. 6 and 7).

Dynamic calculations have been performed by DeepDRiser [7]. Envelops of dynamic tensions (in connected and disconnected mode) and von Mises stresses are presented in Figures 10, 11, 12. In the disconnected mode, the dynamic tension depends mainly on the stiffness of the tensioners assumed to be equal of $2.2 \%$ of the tension. In the Figure 12, no compression is observed in disconnected mode.

\subsection{Conclusions}

The riser is the key element for drilling in ultra-deep water. Its architecture for deepwater drilling depends on numerous different factors related to operational and environmental conditions. These include water depth, mud weight, auxiliary line diameters and working pressures, sea states and current profiles, and maximum rig offset.

The Institut français du pétrole (IFP) has proposed a methodology to optimise the riser design. This methodology is implemented in the DeepDRiser [7] riser software package.

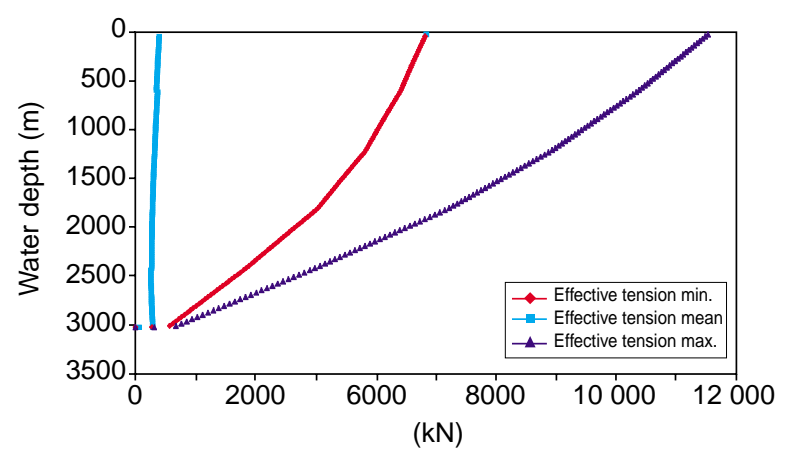

Figure 12

Disconnected mode - Dynamic analysis - Effective tension. Case 2.
Architectures in ultra-deep water are specific for particular conditions. Studies must be performed to determine whether a riser can be used in other environmental or operational conditions. Two factors can radically change the whole architecture of a riser: the integration of auxiliary lines (sliding or hyperstatic) and the disconnected hang off mode (hard or soft). Studies of these particular points must be carried out in the future to improve the design of risers in ultra-deep water.

\section{CLIP RISER}

The Clip Riser was developed in France during the 1980s by IFP and Framatome. More than a decade after its introduction, it is now manufactured and marketed, under license, by Kvaerner Oilfield Products of Houston. Its main purpose is to supply fast and safe connection of riser joints while supporting large-diameter, high-pressure kill and choke lines for ultra-deep offshore drilling applications. Two, 21-in OD (533.4 mm) Clip Risers, manufactured in 1999 and 2000, are in service on the drillships Pride Africa and Pride Angola.

\subsection{A Breech-Block Type Connector}

A drawing of the working principle is presented in Figure 13.

The clip connector is a double breech-block type with a rotating ring and four radial dogs to tighten it. It is made up of three massive forged chromium-molybdenum alloy steel parts with high yield strength (92000 psi-634.8 MPa):

- The box member, which is butt-welded onto the main riser pipe, rests on the spider table during the connection procedure. Externally it has two rows of four $45^{\circ}$ massive lugs each and a thick flange. The lugs in each row are $90^{\circ}$ apart and are designed to take the tensile and bending loads. The four lugs on the bottom row have a slightly larger diameter than the upper ones and are displaced by $45^{\circ}$ in relation to the upper ones. This particular geometry provides an even load distribution between all the mating lugs around a full $360^{\circ}$ circumference. The bottom flange 
is used to rest the box member on the spider dogs and to bolt all the peripheral lines, onto it.

- The pin member which is butt-welded onto the other end of the main riser pipe, has a long stabbing front section that enables the female member to enter with $a \pm 5^{\circ}$ misalignment in any direction. It supports the rotating ring and has a long stabbing front section which contains two lip seal.

- The outer rotating ring ensures the linkage between the pin and the box thanks to the above shoulder and two rows of lugs mating with the corresponding ones on the box.

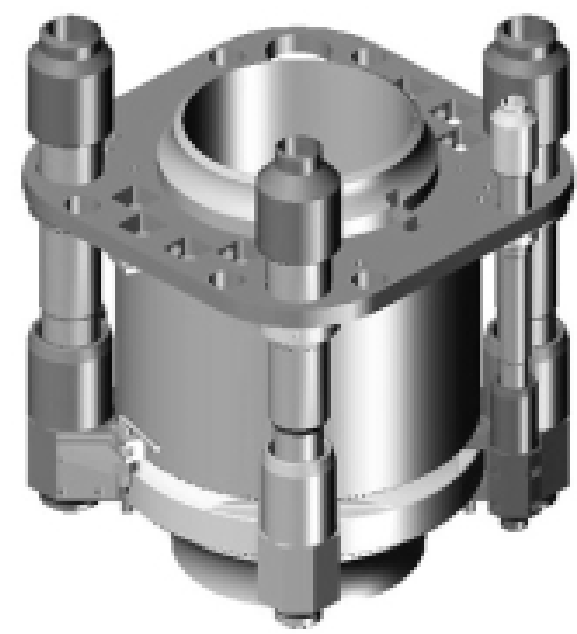

Figure 13

Drawing of the working principle of a breech-block type connector.

The connector also comprises:

- a positioning pin, which allows the outer ring of the connector to be firmly locked in either the fully closed position or the fully open position.

Note: Four tightening dogs used to take up the slight play existing by design between the mating lugs, which allows the free rotation of the outer ring. Elimination of these dogs has been decided for the future.

It should also be mentioned that:

- the end couplings of the peripheral lines (up to eight) are pin and box type with the pin free to slide in the box. The vertical movement is limited by a lock-nut;

- all sliding surfaces are wear resistant and corrosion proof;

- the geometry of the lugs and the profiles of the grooves have been designed to limit the stress levels to within the limits set by the API RP $2 R$ [8].

\subsection{Connecting Procedure}

The connection procedure occurs in five steps once the riser joint has been hung vertically over the box member resting on the spider on the rotary table:

- Once the peripheral lines are aligned, the long pin member is stabbed into box by straightforward self-alignment until it comes to rest on the top shoulder of the box. Correct centring is achieved prior to mating of the outer-line connectors which therefore cannot be damaged.

- The manual positioning vertical pin is removed from the open position.

- A crow-bar is used to rotate the ring one eighth turn $\left(45^{\circ}\right)$ until it comes up against a stopper. Only a slight effort by one man is needed since no torque is required. The lugs on breech-block type ring mate automatically with the corresponding lugs on box to achieve the inter-locked position.

- The positioning pin is put back in place in the closed position. This is to ensure that the full $45^{\circ}$ rotation has been completed. It also prevents any possible back-up of the rotating ring due to jerks by the vessel or the upper riser joint when it is being added to the riser. Once the spider is open and the full weight of the riser is hanging on the lugs, the ring can no longer rotate.

\subsection{Design - Classification}

The final design of this type of connector is based on an extensive analysis of the riser behavior in operation and previous results obtained with the first prototypes. A computer program has been defined and improved with the field results of two drilling campaigns. The design has consisted in sizing and optimising the connector by finite- element analysis for the respective working load by using the Framatome SYSTUS computer model which is used for designing pressure vessels for the nuclear reactors. The analysis has considered two operational modes: connected mode in operation and the hung off mode either during riser running or following a storm induced disconnection at the bottom end.

The design has been fully verified by the following testing programme:

- analysis and verification of calculation by strain measurements in the most highly stressed parts of the connectors under tensile loads;

- fatigue resistance under cycling loads;

- a 6000 kip (2700 t) tensile test of a full scale prototype without any crack;

- test of the resistance and water-tightness at twice the service pressure;

- test of the resistance of the split top guiding plates;

- manoeuvrability test of the connector after each phase with timed measurements of ten repeated make-up sequences. 
In accordance with $A P I 2 R$ requirements [8], the design load of the coupling has been established at 3.5 millions pounds (1575 t).

\subsection{Methodology of the Clip-Riser Fatigue Analysis}

Several improvements of the clip technology are under development by IFP and industrial partners especially concerning the fatigue life of the connector. This can be evaluated with different calculations and experimental tests [9-11]:

- the dynamic behaviour of the riser must be calculated using the finite element method. We take sea states (irregular waves are considered) and mud density into account to be representative of the working life. Stresses in the main pipe are known all along;

- the second phase is the evaluation of the connector stresses. Calculations are made with finite elements in 2D and 3D. They evaluate accurately the stress areas in the connector (maximum stresses are found near the lugs);

- steel characterisation with Wöhler S-N curves have been made. Experimental tests have been made in salt water, test pieces are with and without external coating.

Theoretical working life in fatigue is estimated with these elements depending of the drilling applications (example: $10000 \mathrm{ft}(3048 \mathrm{~m})$ water depth, $17 \mathrm{ppg}$ (2.04) mud weight, 4 1/2" (114.3 mm) ID × 15000 psi $(103.4 \mathrm{MPa})$ kill and choke lines).

Full scale experimental tests complete this study to estimate the connector working life in fatigue.

\subsection{Advantages of the Clip Riser - Conclusion}

The main feature of the Clip Riser is the coupling which allows quick make-up of riser. Considering high rig mobilisation costs, unproductive time is of great concern for operators. Hence it is important for riser couplings to be designed to minimise operating costs by enabling rapid make-up and break-out of connections while maintaining maximum safety and reliability.

The Clip technology is a unique design which does not require bolts, threads or any preloading in operation. A dual row of massive lugs provides a near $-360^{\circ}$ distribution of the axial load and well controlled stress concentrations. Make-up is simple, reliable and very rapid at less than one minute.

Trip times of up to six riser joints per hour have been achieved with the Clip Riser. That is at least twice as fast as the trip times generally achieved with conventional flanged type connectors.

\section{HYBRID STEEL/COMPOSITE KILL AND CHOKE LINE}

The technology presented in this section is designed to reduce riser mass by replacing the existing kill and choke line by lighter tubes. This is achieved using hybrid tubes composed of a steel core hoop wound with a carbon/ polyamide thermoplastic strip. The characteristics of the hybrid tubes are as follows:

- Core steel

- internal diameter: 4 1/2" (114.3 mm)

- thickness: 1/2" (12.7 mm)

- yield stress: $552 \mathrm{MPa}$.

- Composite hooping

- $50 \%$ carbon fibres

- $50 \%$ polyamide 12 .

During fabrication of the hybrid tube, the tension applied to the composite strip is carefully controlled.

Hybrid kill and choke lines are lighter than equivalent steel tubes. This leads to many benefits in the form of reduced buoyancy, reduced top tension and improved dynamic behavior, as explained below.

\subsection{Working Principle of the Hybrid Tube}

Hybrid kill and choke lines have to withstand axial loads (imposed by the lock-nut mentioned above) as well as high internal pressures up to $15000 \mathrm{psi}(103.4 \mathrm{MPa})$, according to the BOP series. Such lines would normally require a 1" $(25.4 \mathrm{~mm})$ or more wall thickness. However the use of composite material hoop-wound around the steel core allows the wall thickness to be reduced to $1 / 2 "(12.7 \mathrm{~mm})$. This thickness is compatible with the axial loads. The composite windings contribute to the burst resistance.

An operating diagram is given in Figure 14 where hoop stresses in the steel core and composite hoop windings are plotted as a function of pressure.

The carbon strip provides a prestress of $200 \mathrm{MPa}$. During the first stage, the steel core resists the internal pressure until the hoop stresses reach the yield stress of the steel. An internal pressure of at least $22500 \mathrm{psi}(155.2 \mathrm{MPa})$ is required before this occurs (see Paragraph 3.2). Any further increase in the internal pressure is resisted by the composite hoop windings.

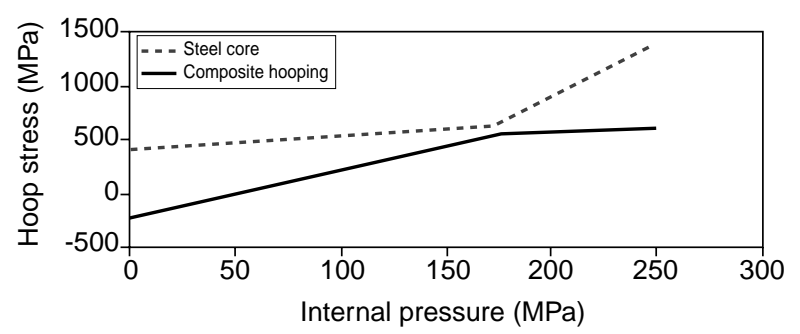

Figure 14

Working principle of the hybrid tube. 
The strip works then under axial forces due to circumferential winding. Failure of the hybrid tube occurs when the fibres of the strip are broken. Many tests have been carried out at IFP to establish the number of composite layers required to meet particular specifications of kill and choke lines.

\subsection{Design Criteria}

Criteria adopted for the design of the hybrid lines are as follows:

- Composite hooping:

- after hoop winding the strip at $20^{\circ} \mathrm{C}$ : maximum tension in the strip to be less than $1 / 3$ failure tension for the strip (at $20^{\circ} \mathrm{C}$ );

- at internal working pressure of $15000 \mathrm{psi}(103.4 \mathrm{MPa})$ and $100^{\circ} \mathrm{C}$ : maximum tension in the strip to be less than $50 \%$ of the strip failure tension (at $100^{\circ} \mathrm{C}$ );

- at internal test pressure of $22500 \mathrm{psi}(155.2 \mathrm{MPa}), 20^{\circ} \mathrm{C}$ and maximum axial load (160 t): tension in the strip to be less than $50 \%$ of the strip failure tension (at $20^{\circ} \mathrm{C}$ ). This condition corresponds to a proof test of the complete line with plugs before installation in the riser during which the tube is subjected to axial load.

- Steel core:

- after hoop winding the strip and at $20^{\circ} \mathrm{C}$ : maximum von Mises stress to be less than $2 / 3$ of yield;

- at internal service pressure of $15000 \mathrm{psi}(103.4 \mathrm{MPa})$ and $100^{\circ} \mathrm{C}$ : maximal von Mises stress to be less than $2 / 3$ of yield;

- at internal test pressure of $22500 \mathrm{psi}(155.2 \mathrm{MPa}), 20^{\circ} \mathrm{C}$ and axial load (160 t): maximum von Mises stress to be less than of yield;

- at external collapse pressure of $4350 \mathrm{psi}(30 \mathrm{MPa})$ and $20^{\circ} \mathrm{C}$ : maximal von Mises stress to be less than of yield.

\subsection{Optimal Design}

A computer program has been developed at IFP to design hybrid tubes under different conditions of pressure (internal, external), axial loads, temperature [12]. Finally, this software has allowed the design to be optimised and the thickness of the composite layer to be minimised (while respecting allowable strip tensions during fabrication). The optimal design consists of $5 \mathrm{~mm}$ of composite hooped around the tube with a near $2400 \mathrm{~N}$ maximum tension. The tension is carefully controlled during fabrication in order to have obtain near constant stresses in the composite.

Results obtained with the optimal design are presented in Table 5.

As can be seen, the optimal design respects the criteria.

\subsection{Qualification tests (Figs.15 and 16)}

Ten prototypes of the above design have been built by Composites Aquitaine (South west of France) and tested by IFP.
TABLE 5

Optimal design results

\begin{tabular}{|c|c|c|}
\hline Composite wall thickness (mm) & \multicolumn{2}{|c|}{5.04} \\
\hline Maximal hoop tensions $(\mathrm{N})$ & \multicolumn{2}{|c|}{$\sim 2400$} \\
\hline Composite linear weight $(\mathrm{kg} / \mathrm{m})$ & \multicolumn{2}{|c|}{3.1} \\
\hline \multicolumn{2}{|l|}{ After hooping the strip and at $20^{\circ} \mathrm{C}$} & Criteria \\
\hline Maximal von Mises stress in steel (MPa) & 203 & $<368$ \\
\hline Maximum tension in strip $(\mathrm{N})$ & 1964 & $<2162$ \\
\hline \multicolumn{3}{|c|}{ Under internal pressure of $15000 \mathrm{psi}(103.4 \mathrm{MPa}) / \mathrm{at} 100^{\circ} \mathrm{C}$} \\
\hline Maximum von Mises stress in steel (MPa) & 320 & $<368$ \\
\hline Maximum tension in strip $(\mathrm{N})$ & 2967 & $<3507$ \\
\hline \multicolumn{3}{|c|}{ Under internal pressure of $22500 \mathrm{psi}(155.2 \mathrm{MPa}) / \mathrm{at} 20^{\circ} \mathrm{C} / 160 \mathrm{t}$} \\
\hline Maximum von Mises stress in steel (MPa) & 569 & $<574$ \\
\hline Maximum tension in strip $(\mathrm{N})$ & 2786 & $<3244$ \\
\hline \multicolumn{3}{|c|}{ Collapse pressure $(4350 \mathrm{psi}-30 \mathrm{MPa}) / 20^{\circ} \mathrm{C}$} \\
\hline $\begin{array}{l}\text { Maximum von Mises stresses } \\
\text { in the steel }(\mathrm{MPa})\end{array}$ & 354 & $<574$ \\
\hline Maximum tension in the strip (N) & 1668 & $>0$ \\
\hline \multicolumn{3}{|l|}{ Burst at $20^{\circ} \mathrm{C}$} \\
\hline Burst pressure (psi) & 35500 & 33750 \\
\hline (MPa) & 244.7 & 244.7 \\
\hline
\end{tabular}

The various tests have been chosen to be representative of the whole working life of kill and choke lines:

- simple burst at ambient temperature;

- burst with temperature: internal and external temperature $100^{\circ} \mathrm{C}$;

- burst with temperature simulating offshore conditions: internal temperature $100^{\circ} \mathrm{C}$; external temperature $4^{\circ} \mathrm{C}$;

- long-term temperature test: $100^{\circ} \mathrm{C}$ for $120 \mathrm{~h}$, followed by burst test;

- long-term pressure test: internal pressure of 22500 psi (155.2 MPa) for one month, followed by burst test;

- cyclic temperature test: from $0^{\circ}$ to $100^{\circ} \mathrm{C} ; 100$ times, followed by burst test;

- cyclic pressure test: from 150 psi to 22500 psi (155.2 MPa) 10000 times, followed by burst test;

- external pressure collapse test.

The transition section between the hybrid tube and the end fittings have been studied with special attention. Tests on this particular part will be carried out to check the geometry (angle, number of strips):

- burst in temperature to simulate offshore conditions: internal temperature $100^{\circ} \mathrm{C}$ and external temperature $4^{\circ} \mathrm{C}$;

- cyclic pressure test: 150 psi to 22500 psi (155.2 MPa); 10000 times followed by burst test. 


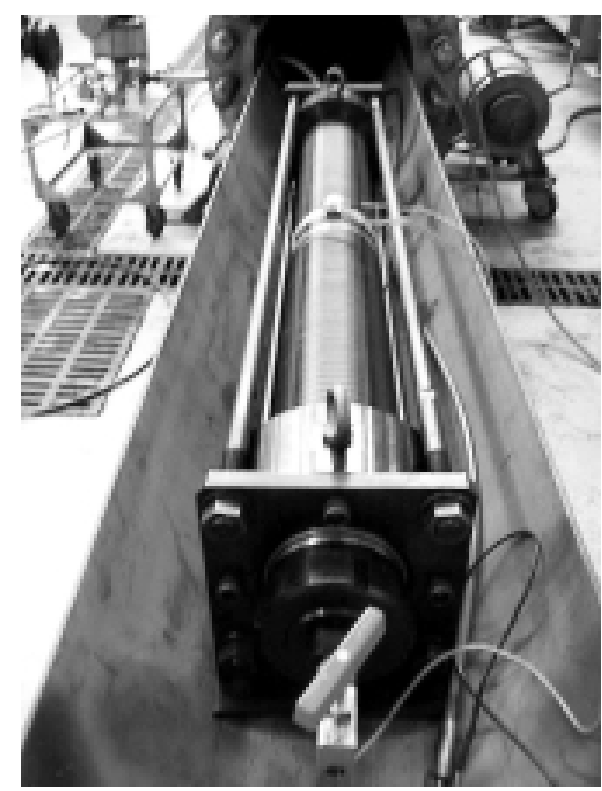

Figure 15

Hybrid tube in its burst assembly.

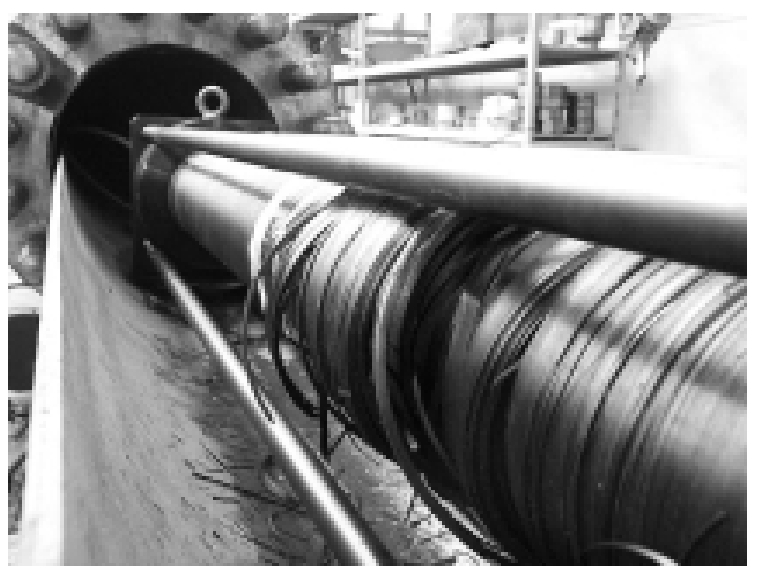

Figure 16

Hybryd tube after bursting.

The set of tests are designed to prove the satisfactory behavior of the hybrid tubes and the transition sections in severe working condition.

Each tube has been fully instrumented with strain gauges and pressure sensors in order to detect the yield strength of the hybrid tube and also the pressure value of the burst. All the bursts have been surveyed by Bureau Veritas to attest the bursting pressure values.

The results of the qualification tests are presented in the Figure 17.

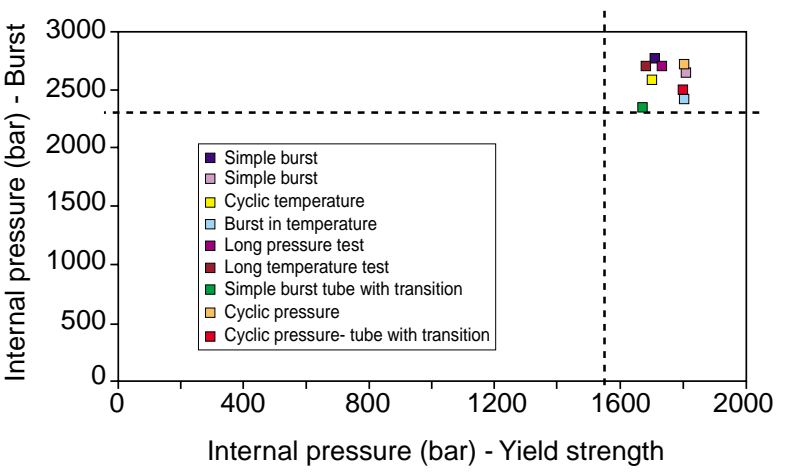

Figure 17

Hybrid tubes - Qualification test results $(1 \mathrm{bar}=0.1 \mathrm{MPa})$.

The design proposed respects the specifications of choke and kill lines. This design could be chosen for hybrid tube development.

\subsection{Prototype Manufacturing and Field Testing on a Drillship}

The next step of the project is to build three lines, each $22 \mathrm{~m}$ long; to fit them to an operational riser joint and to test them on a real riser. These prototypes will be build late 2000 .

Firstly two of the prototypes will be used to replace the booster line on two riser joints for six months. Then the three hybrid lines will be used to replace the booster line and the kill and choke lines of one riser joint..

The tests will be carried out on either the Pride Africa or the Pride Angola drillship during operations off the Angola coasts in 2001.

Following the campaign, all the prototypes will be brought back to France and burst in IFP facilities to evaluate the influence of operational conditions on the performance of the tubes.

\subsection{Advantages of Hybrid Tubes and Conclusions}

The characteristics of hybrid kill and choke lines are compared with those of all steel line in the Table 6 .

As can be seen, the weight of the hybrid line is half that of the equivalent steel line.

In the Table 4 (case 2 and 3), the architectures of risers with the two types of kill and choke lines are compared. Conditions are for the Gulf of Mexico ( $T p=12.6 \mathrm{~s}$ and $H s=7.6 \mathrm{~m}$ in stand-by mode) with $3000 \mathrm{~m}$ water depth and 2.04 mud density.

These architectures respect $A P I$ recommendations which limit the maximum allowable von Mises stresses in the main pipe to $2 / 3$ of the yield stress in operational conditions. In stand by mode (hard hang off situation), no negative 
TABLE 6

Comparison between steel and hybrid choke lines

\begin{tabular}{l|c|c}
\hline & Steel & Hybrid \\
\hline Internal diameter & $4^{\prime \prime} 1 / 2$ & $4 " 1 / 2$ \\
$114.3 \mathrm{~mm}$ & $114.3 \mathrm{~mm}$ & $114.3 \mathrm{~mm}$ \\
\hline Steel thickness & $1^{\prime \prime}$ & $1 / 2^{\prime \prime}$ \\
& $25.4 \mathrm{~mm}$ & $12,7 \mathrm{~mm}$ \\
\hline Composite thickness & - & $7 \mathrm{~mm}$ \\
\hline Outside diameter & $6 " 1 / 2$ & $6 "$ \\
& $165.1 \mathrm{~mm}$ & $152.4 \mathrm{~mm}$ \\
\hline Service pressure & $15000 \mathrm{psi}$ & $15000 \mathrm{psi}$ \\
& $103.4 \mathrm{MPa}$ & $103.4 \mathrm{MPa}$ \\
\hline Test pressure & $22500 \mathrm{psi}$ & $22500 \mathrm{psi}$ \\
& $155.2 \mathrm{MPa}$ & $155.2 \mathrm{MPa}$ \\
\hline Linear dry weight & $87.4 \mathrm{~kg} / \mathrm{m}$ & $44.0 \mathrm{~kg} / \mathrm{m}$ \\
\hline
\end{tabular}

tension (dynamic compression) is allowed. This is obtained by fixing the apparent weight of the riser at least equal to the maximum dynamic fluctuation of tension amplitude created by the heave of the vessel. The API recommendation of a $2^{\circ}$ maximum bottom angle leads to the requirement for $100 \mathrm{t}$ tension at the riser bottom end.

As can be seen from the table hybrid lines lead to the following improvements in riser characteristics:

- reduction of the riser mass $(\sim 450 \mathrm{t})$;

- reduction of the required buoyancy $(\sim 190 \mathrm{t})$ and of buoyancy module diameter $(\sim 3 \Leftrightarrow 76 \mathrm{~mm})$;

- reduction of the required top tension $(\sim 60 \mathrm{t})$;

- reduction of the natural period of the riser $(\sim 0.3 \mathrm{~s})$.

The reduction of the riser mass is due to the lightweight hybrid tubes and the associated buoyancy weight saving on deckload can lead to an economy of several US dollars per pound. Similarly, the savings due to reduction in riser tension represent also several dollars per pound. The overall system savings can be of the order of 2-3 MUS\$ for the case considered without taking into account the cost savings for the buoyancy modules.

The reduced mass leads to reduce axial dynamic loads in the hung off mode. The reduced natural period leads to reduced dynamic amplification, which further reduces axial dynamic loads. Hence hybrid tubes significantly reduced axial fatigue in the hung off mode. The technical and economic advantages of risers with hybrid tubes imply it is well suited to ultra deep drilling in very harsh environments.

Moreover this technology is particularly well suited for the upgrading of existing risers. The current $10000 \mathrm{psi}$ (69 $\mathrm{MPa}$ ) lines can be replaced by hybrid 15000 psi (103.4 MPa) tubes without increasing weight. Similarly existing 3" (76.2 mm) ID lines can be replaced by hybrid 4" (101.6 mm) or 4 1/2" (114.3 mm) ID lines.

\section{HYPERSTATIC INTEGRATION SYSTEM (HIS)}

Drilling in ultra deep water and in very harsh operational and oceanographic environment requires risers having the following characteristics:

- Large mass and weight in water (particularly when full of heavy mud) leading to very high top tension requirements $(\geq 1000 \mathrm{t})$.

- High axial strength requirements to resist the tension plus the pressure end effect of the peripheral lines (PL) which can contribute an additional $400 \mathrm{t}$.

- Suppression of buoyancy modules at the bottom part of the riser in order to improve the axial behavior in hung off mode and to decrease the natural period.

- Reducing as much as possible the dead weight of the structure. This dead weight, such as buoyancy modules and peripheral lines, does not contribute to the axial resistance of the riser. In the example given in Paragraph 1.5 (Table 4), The structural efficiency (ratio of the axially working mass to the total mass of the riser) is about $33 \%$.

- High dynamic loads which can lead to fatigue of the main tube (MT) and the connectors.

The HIS leads to interesting improvements in all these areas.

\subsection{Principle of the HIS}

In this system, the peripheral lines are integrated so that they participate in the axial resistance of the riser. The lines play a structural role in the riser instead of being merely dead weight.

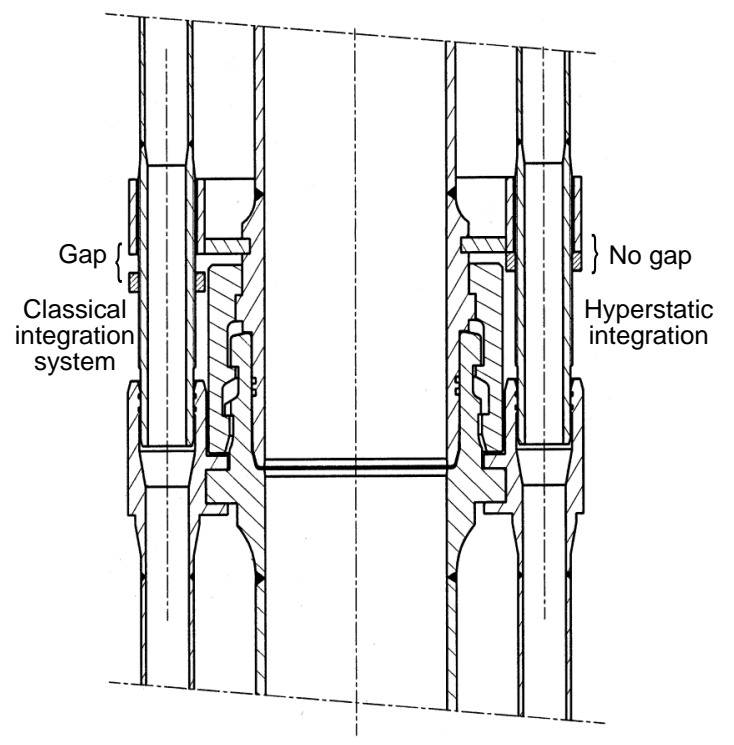

Figure 18

Schematics of hyperstatic integration. 


\section{Present System Integration}

The Figure 18 shows the present system of peripheral line integration. The lines are fixed to the connector at one extremity of each riser joint and are free to slide at the other extremity. Hence they do not participate in sharing axial riser loads.

This system is simple but has the following disadvantages:

- relative movement between the riser main tube and peripheral lines can be significant ( 1 " to $2 " \Leftrightarrow 25-50 \mathrm{~mm}$ ). The tubes are subjected to independent and different loads due to pressure, tension, temperature and bending effects. Then the geometry of the seal box is relatively complex to allow such motions;

- the mass of the peripheral lines is nonstructural;

- the peripheral lines are subjected to effective compression when under pressure which can lead to buckling. Clamps are required to avoid such buckling which increases the mass of the riser.

The new system of integration avoids all these difficulties.

\section{Hyperstatic Integration System}

The new system consists of fixing the peripheral lines to the main riser tube at both extremities of each riser joint. As a result the lines participate in resisting axial riser loads. The stress distribution between the main tube and the peripheral lines is governed by the laws of hyperstatics.

\subsection{Presentation of the Model and Tests Carried Out}

A model has been built at IFP to evaluate the stress distribution between the peripheral lines and the main tube and to validate theoretical computation. The model consists of a small-scale riser joint (1/4) (Fig. 19). It has a main tube and 2 peripheral lines. The integration system can be modified easily to simulate either a standard integration (with sliding end) or an hyperstatic integration system by changing the gap of a stop ring. Three clamps have been added to the model. These clamps have been designed to either maintain the peripheral lines in a straight position or to allow buckling (with a radial gap). Each tube can be pressurised independently and the whole structure can be tensioned using a hydraulic jack. Moreover the peripheral lines can be heated by means of special belts to simulate temperatures effects.

The testing programme consists in applying tension internal pressure and temperature in different configurations as defined below. The model has been instrumented with:

- stress gauges;

- motion sensors;

- temperature sensors;

- pressure sensors.

Many tests have been carried out in the IFP' workshop including:

- buckling test of each peripheral line with different clamp configurations;

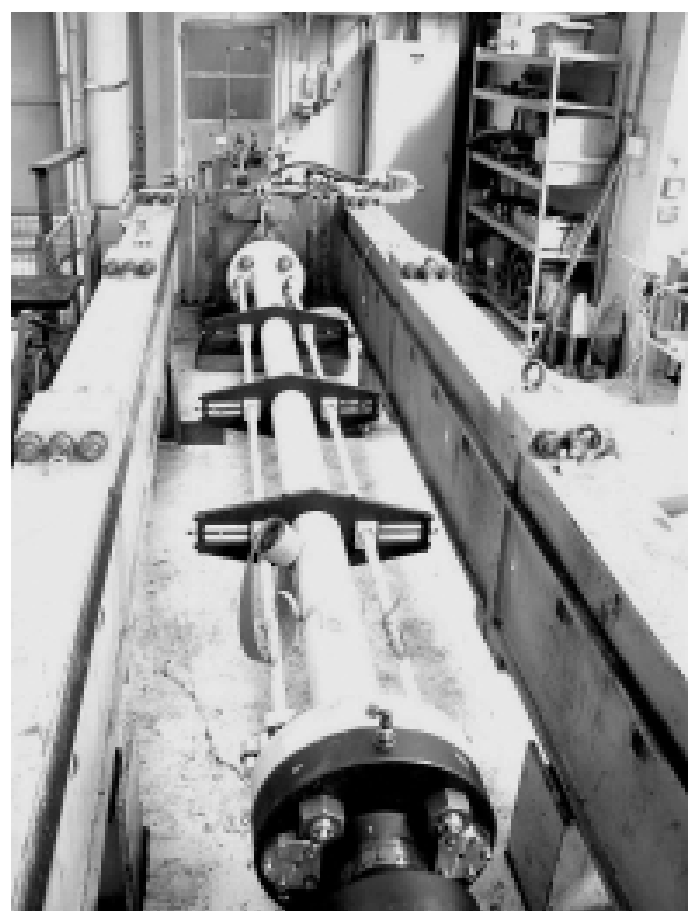

Figure 19

Model for the HSI integration.

- general behavior of the model with classical integration system (different internal pressures in the MT or PL with or without axial loads);

- general behaviour of the model with hyperstatic integration system (different internal pressures in the MT or PL with or without axial loads);

- general behavior of the model with mixed integration system (different internal pressures in the MT or PL with or without axial loads). A small gap of the stop ring is set and the peripheral lines are sometimes in hyperstatic sometimes in sliding mode.

\subsection{Advantages of the Hyperstatic Integration System}

The preliminary development phase of the hyperstatic riser system has led to the following initial conclusions:

- the wall thickness of the main pipe (and hence the riser mass) can be significantly reduced. This reduction leads to a large decrease in the quantity of buoyancy required;

- the peripheral lines are maintained in positive effective tension in all configurations. This implies that clamps are no longer required for preventing buckling;

- no sliding problem occurs in the peripheral line end fittings because the lines are linked to the connector. The design is thus simplified; 
- possibility of using hybrid tubes (see Paragraph 3.3) to decrease the mass of the peripheral lines. In this case, the distribution of stresses between the tubes (main pipe and peripheral lines) is improved since the peripheral lines are less thick;

- the composite hoop windings could also be beneficially applied to lower part of the riser main tube leading to a reduction in wall thickness. In the hyperstatic integration system this thickness is governed by the internal pressure (instead of axial tension).

The Table 7 compares the characteristics of a classical riser with those of a hyperstatic riser fitted with:

- hybrid steel/composite kill and choke lines;

- main tube hoop with carbon strips below 2000 m water depth.

TABLE 7

Comparison between classical and hyperstatic architecture

\begin{tabular}{l|c|c}
\hline $\begin{array}{l}\text { Kill and choke lines } \\
\text { Integration principle }\end{array}$ & $\begin{array}{c}\text { Steel } \\
\text { Classical }\end{array}$ & $\begin{array}{c}\text { Hybrid } \\
\text { Hyperstatic }\end{array}$ \\
\hline Water depth (m) & $\mathbf{3 0 0 0}$ & $\mathbf{3 0 0 0}$ \\
\hline Buoyancy module diameter & $53 "$ & $48 "$ \\
$1346 \mathrm{~mm}$ & $1219 \mathrm{~mm}$ \\
\hline Natural period (s) & 5.0 & $<3.5$ \\
\hline Riser mass (t) & $\mathbf{3 3 7 1}$ & $\mathbf{2 5 9 1}$ \\
\hline Riser app. wt. $(\mathbf{t})$ & $\mathbf{3 7 3}$ & $\mathbf{2 0 4}$ \\
\hline Mud app. wt $(\mathbf{t})-\boldsymbol{d}=\mathbf{2 . 0 4}$ & $\mathbf{6 4 9}$ & $\mathbf{6 8 2}$ \\
\hline Bottom tension $(\mathbf{t})$ & $\mathbf{1 0 0}$ & $\mathbf{1 0 0}$ \\
\hline Top tension* (t) & $\mathbf{1 1 7 2}$ & $\mathbf{1 0 3 6}$ \\
\hline
\end{tabular}

*Top tension including slip joint weight (50 t).

As can be seen, the dry weight (mass) of a riser with hyperstatic integration is $780 \mathrm{t}$ less than that of a classical steel riser. The required top tension is reduced by at least $136 \mathrm{t}$. The buoyancy material is reduced by $284 \mathrm{t}$.

As mentioned in Paragraph 3.6, such savings are of great importance for the drillships design and the riser management economy. The relatively low mass of the riser and the fact that its resonant period of axial vibrations is well below the usual wave range lead to important improvements in the dynamic behavior of the system, both in drilling and hang off modes. This leads enlarged operating envelopes and improved fatigue life for the riser.

The hyperstatic integration system with hybrid tubes (main tube and peripheral lines) is plainly well suited for ultra deep water applications and is now under development at IFP.

\section{CONCLUSION}

IFP has developed tools and technology to answer the waiting of contractors that wish to drill in deeper water depths, in harsher environment with higher mud weight.

The methodology aims to optimise the riser design by proposing practical guidelines implemented by a software. As we discussed it, architectures in ultra-deep water are specific for particular conditions. Studies must be performed to determine whether a riser can be used in other environmental or operational conditions. Other studies should be carried out by considering hyperstatic integration of auxiliary lines and soft hang off in stand by mode.

To reduce unproductive time on the rig during the drilling, the Clip Riser has been developed. The main feature of the Clip Riser is the coupling which allows quick make-up of the riser. The clip technology is a unique design which does not require bolts, threads or any preloading in operation.

Make-up is simple, reliable and very rapid (less than one minute), twice as fast as usual flange connectors. Because of all these advantages, the Clip Riser is particularly well suited for ultra deep drilling in harsh environments.

To reduce drillship deckload and required tensioning capacity, the hybrid tubes have been developed to replace the existing 4"1/2 ID steel kill and choke lines by lighter tubes. The hybrid tubes are $50 \%$ lighter than equivalent all steel lines, which leads to a reduction of $500 \mathrm{t}$ on a $3000 \mathrm{~m}$ riser. The reduced mass leads to reduce the top tension, axial dynamic loads in hung off mode. Hence, hybrid tubes significantly reduce axial fatigue of the riser.

To improve axial behaviour of the riser and riser architecture, hyperstatic integration of choke and kill lines have been studied. This consists in fixing the auxiliary lines at each riser joint so that they can participate to the axial resistance of the riser. This system leads to reduce significantly the wall thickness of the riser, to reduce the axial period of the riser. The lines are maintained in positive effective tension so that clamps are no longer required. Finally, this hyperstatic integration system leads to enlarged operating envelopes and improved fatigue life of the riser.

\section{REFERENCES}

1 API RP 16Q (1993) API Recommended Practice for Design, Selection, Operation and Maintenance of Marine Drilling Riser Systems, First edition (Formerly RP 2Q and RP 2K).

2 Sparks, C.P. (1984) The Influence of Tension, Pressure and Weight on Pipe and Riser Deformations and Stresses. Transactions of ASME, Journal of Energy Resources Technology, 106.

3 Heurtier, J.M., Biolley, F. and Berhault, C. (1998) Fully Coupled Dynamic Analysis of Rigid Lines. Proceedings of ISOPE 98, Montreal, Canada, 246-252

4 Brekke, J.N. (1999) Behavior of a Drilling Riser Hung off in Deep Water. 11th annual Deep Offshore Technology, Stavanger. 
5 Sparks, C.P. (1980) Mechanical Behavior of Marine Risers. Mode of Influence of Principal Parameters. Transactions of ASME, Journal of Energy Resources Technology, 102

6 Gaillard, C., Guesnon, J., Sparks, C.P. and Kerbart, Y. (2000) Riser Technology for Ultra Deep Water Drilling. 12th Deep Offshore Technology, New Orleans.

7 Gaillard, C., Guesnon, J., Sparks, C., Le-Buhan, P. and Kerbart, Y. (2001) Guidelines for the Design of Ultra Deep Water Drilling Risers. IADC Drilling Northern Deep Water 2001 Conference and Exhibition, Stavanger.

8 API RP 2R (1984) API Recommended Practice for Design, Rating and Testing of Marine Drilling Riser Couplings, First edition.
9 Lalanne, C. (1999) Vibrations et chocs mécaniques - Dommage par fatigue, tome 4.

10 Wirsching, P.H. and Light, M.C. (1980) Fatigue under Wide Band Random Stresses. Jl of the Structural Division, ST7, Paper 15574.

11 Wirsching, P.H. (1979) Fatigue Reliability in Welded Joints of Offshore Structures. Offhore Techn. Conf., OTC Paper 3380.

12 Gaillard, C. and Guesnon, J. (2001) Hybrid Tube Design and Qualification. IFP Internal Report no. 56449.

Final manuscript received in October 2001 